\title{
NIH ethics office clamps down on Duke ...
}

[WASHINGTON] Duke University Medical Center (DUMC) has won a reprieve after the federal government shut down all its research involving human subjects last week. Federal regulators lifted the ban four days later, on condition that a number of remedial measures were taken immediately at the centre in Durham, North Carolina.

Among other things, the centre's Institutional Review Board (IRB), which is responsible for giving ethical approval to experiments, will have to re-review 274 of roughly 2,000 clinical trials which were approved when the panel lacked a quorum.

The centre will also have to immediately re-educate panel members and researchers on the federal regulations protecting human welfare in government-funded research. And it must set up a second IRB by 26 May, rather than by October, as had been planned, to relieve the overwork of the existing one.

Although there was no evidence that human research subjects have suffered at Duke, the decision on 10 May to shut down \$140 million-worth of government-funded research was taken because procedures to prevent this had not been properly followed.

The Office for Protection from Research Risks (OPRR) at the National Institutes of Health (NIH) cited 20 problems, ranging from meetings lacking quorums to conflicts of interest by voting IRB members who were university grants and contracts officials.

"The difficult work now begins," says Gary Ellis, director of the OPRR. "Building a broad and deep programme of protecting human subjects is going to take some time."

Ralph Snyderman, the chancellor for health affairs at DUMC, said in a statement

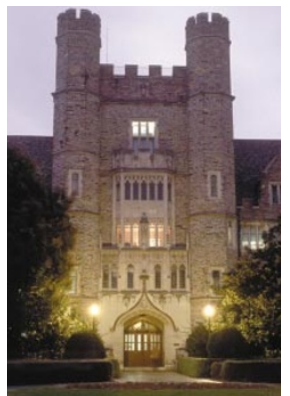

Under fire: Duke's medical centre that officials there are "pleased" about the reinstatement. "We always have and will continue to place the safety of our study subjects as our highest priority," he said, adding that new programmes will "further ensure institutional oversight."

The shutdown is the third in seven months instigated by OPRR, the $\$ 2.5$ million $\mathrm{NIH}$ office responsible for ensuring the safety of human and animal subjects in research funded by the Department of Health and Human Services, of which NIH is a part.

Last autumn, OPRR shut down humansubjects research at a medical centre in Chicago for four days. In March, it did the same at the veterans' hospital system in Los Angeles (see Nature 398, 448; 1999), a move later extended by the Department of Veterans Affairs to encompass all research, basic and clinical, in the Los Angeles system (see box.) Before this, OPRR had not shut down human research since 1989, and it had never targeted an institution as well known as Duke.

Last week's action was "the nuclear bomb of enforcement”, says Arthur Caplan, a bioethicist and former IRB member at the University of Pennsylvania. "At a major research university, to suspend funding even temporarily is an almost unprecedented event."

Some observers speculate that the pace of shutdowns and the high profile of Duke suggest that the OPRR is trying to toughen

\section{as basic scientists feel the pinch in LA}

[WASHINGTON] Although the research shutdown at Duke University Medical Center (see above) only affected clinical researchers, basic scientists have been feeling the pain at the veterans' affairs (VA) hospital system in Los Angeles.

The NH's Office for Protection from Research Risks shut down humansubjects research in the VA system in late March. But days later, a heavier blow landed: the Department of Veterans Affairs in Washington extended the ban to encompass research in the Los Angeles VA system in its entirety (see
Nature 398, 448; 1999). The move was "equivalent to shutting down the US Air Force if you find a scandal in the Air Force Academy", complains George Sachs, a professor of medicine at UCLA and a senior medical investigator at the Veterans Affairs Medical Center West Los Angeles, where he is director of the laboratory of membrane biology.

Sachs, who studies the biology of duodenal ulcers, has lost the support of two $\mathrm{NIH}$ grants and a VA grant. He says he has put more than $\$ 5,000$ of debt on his credit card, buying everything from DNA primers to computer software in order to keep experiments running. Because local officials have said that "maintenance" research can proceed, Sachs is allowed to continue with some work that is already under way, but cannot start new projects. However, he says that many of his funding requests, which now must be routed through Washington, have been turned down. And some items are not to be had at all, including animals. So one postdoc, due to return to Germany this month, will leave without finishing his work on rabbit gastric glands. up its image just as its political fortunes are coming into the balance.

In two weeks, the advisory committee to $\mathrm{NIH}$ director Harold Varmus is due to receive a report considering whether OPRR has enough authority and looking at its placement within NIH. Critics say it is hard pressed to execute its mission of regulating work sponsored by the agency which controls its fate (see Nature 397, 550; 1999).

The report is expected to recommend, at least as an option, that OPRR be elevated to the office of the secretary of Health and Human Services. "OPRR has ratcheted up the level of scrutiny and stringency [of IRBs]," says David Korn of the Association of American Medical Colleges. "One speculation is that OPRR has decided it's time to flex its muscles and show that it really is out there doing its job."

Others argued that even elevating OPRR within the Department of Health and Human Services would not give it enough independence. The suggestion that an independent body should monitor all government-sponsored research involving humans is hinted at in a letter to President Clinton made public by the National Bioethics Advisory Commission (NBAC) on 14 May, the day that Duke's research was reinstated.

Harold Shapiro, the NBAC chairman, writes that government ethics rules are difficult to enforce and improve "in part because no single authority or office oversees research protections across all government agencies and departments". The commission is due to make formal recommendations later this year for changes in the government system for protection of human subjects.

Ellis denies that his office has launched a get-tough strategy, and points out that the suspensions in Chicago and Los Angeles came after disputes lasting four and six years, respectively.

In none of the three cases did OPRR allege injury to human subjects. Rather, it targeted IRBs for lapses such as failing to include public representatives and failing to conduct continuing reviews of research trials that are required at least yearly.

The US media, advocacy groups and Congress however, have increasingly scrutinized human experimentation in the past two years. Several newspaper and television stories have focused on lapses in patient protection, particularly in psychiatric research.

This has also been examined by NBAC, which in December issued recommendations for improving research protection for the mentally ill. And the Inspector General of the Department of Health and Human Services last year issued a report saying that the IRB system was "in jeopardy" (see Nature 393, 610; 1998).

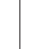

